\title{
On the Occurrence of Cytomixis: A Case Study in Rauwolfia tetraphylla L.
}

\author{
Ajay Kumar Bariar ${ }^{1}$ \\ Department of Botany, \\ S. S. Memorial College, Ranchi 834008 , India
}

Accepted November 23, 1983

The extrusion, migration and mixing of chromatin materials between cells of the meristematic tissues have been referred to as Cytomixis. In most of the plant and animal materials the process were generally recorded in the spore mother cells, however, few cases of mitotic cytomixis have also been reported (Bobak and Henrich 1978). It appeared from the available literatures that the process could be effectively induced by the use of mutagens, clastogens and carcinogens (Gates 1911, Bell 1974, Morriset 1978).

In the present communication it is proposed that these abnormal movements in the chromatin materials were due to anomalous spindle behaviour and were controlled by a gene or genes.

\section{Materials and methods}

Dry and dormant seeds of Rauwolfia tetraphylla L. were treated with gamma irradiations from $\mathrm{Co}^{80}$-source at doses 5, 10, 15, 20 and $25 \mathrm{KR}$. Young and healthy floral buds were collected at random from the plants raised from the seeds. These buds were fixed in $1: 3$ aceto-alcohol between 10 to 11 A.M. and left in this solution for an overnight. The fixed materials were then transferred to 70 percent alcohol for preservations.

The staining was carried out in $2 \%$ acetocarmine and slides were prepared by squash technique. Approximately one thousand pollen mother cells were scored in each treatment and the percentage of cytomictic cells were recorded. The buds collected from the untreated plants were considered as controls.

\section{Observations}

The results obtained have been set forth in Table 1 and Figure 1. The perusal of the table indicated that the percentage of cytomictic pollen mother cells were in exponential relationship with the dose of the gamma irradiations and were altogether absent in the control populations. There was a sharp increase in the cytomictic PMCs between 10 to $20 \mathrm{KR}$ dose level.

The microphotograph (Fig. 1) indicated that the PMCs involved in cytomixis were undergoing meiotic I division, consisting eventually of haploidisation of the

1 Permanent Address: Court-Road, Giridih: 815301, India. 
PMCs and formation of two sister dyads. The cytokinesis, that is the onset of telophase occurred when the chromatin materials were stationed at the equatorial region, as a result two cytoplasmic compartments were formed, one possessing both the chromatin sets and the other without any. The term chromatin was used here to connote the loose and meshy nature of the chromosomes. Each of the cytoplasmic compartments has been referred as sister dyads because both possessed a well developed

Table 1. Percentage of cytomictic pollen mother cells showing abnormal chromatin movement.

\begin{tabular}{cccc}
\hline $\begin{array}{c}\text { No. of } \\
\text { obs. }\end{array}$ & Dose in kilorads & $\begin{array}{c}\text { No. of cytomictic PMCs } \\
\text { out of } 1000 \text { scored. }\end{array}$ & $\begin{array}{c}\text { Percentage } \\
\text { of cytomictic PMCs }\end{array}$ \\
\hline 1 & Control & - & - \\
2 & $5 \mathrm{KR}$ & 24 & 2.4 \\
3 & $10 \mathrm{KR}$ & 28 & 2.8 \\
4 & $15 \mathrm{KR}$ & 39 & 3.9 \\
5 & $20 \mathrm{KR}$ & 51 & 5.1 \\
6 & $25 \mathrm{KR}$ & 56 & 5.6 \\
\hline
\end{tabular}

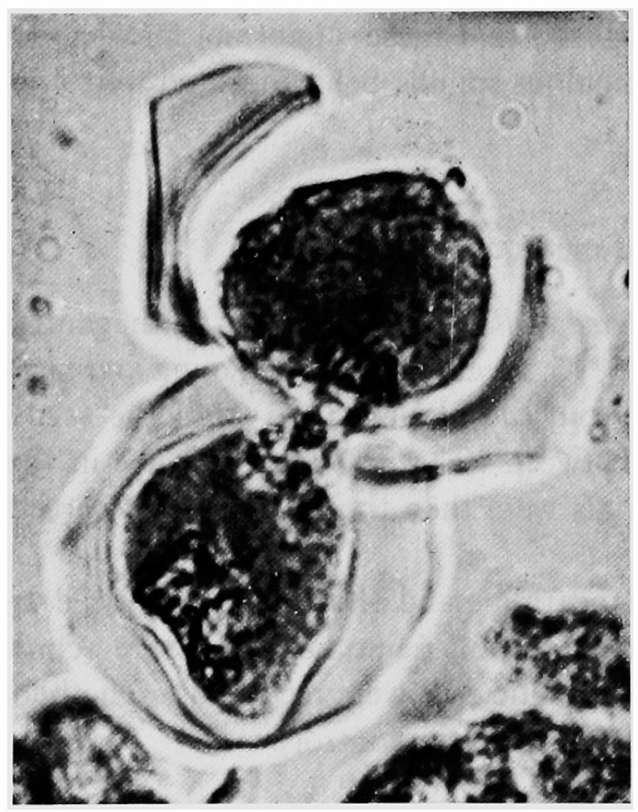

Fig. 1. The pollen mother cell undergoing anaphase-telophase I at the same time showing cytokinesis, leading to the formation of two unseparated daughter dyads. wall. The dyads so formed after meiotic I division were of equal size and appeared normal. One set of the chromatin net work already reached its pole while the other set was in the process of migration to its respective pole, which appeared as extrusion or mixing of the chromatin materials between adjacent cells. No other chromosomal aberrations like bridges, fragments and laggards were observed in these types of cells.

\section{Discussions}

The process as shown in the figure has been referred as cytomixis by Gates (1911), who reported such phenomenon for the first time in Oenothera gigas. Since then many attempts have been made to explain the mechanism behind the apparent migrating chromatin materials. It has been considered as purely an accidental event (Kamra 1960), some considered these as a manifestation of pathological change (Bobak and Henrich 1978) while others were of the opinion that it was due to some unknown physiological disturbances leading to aberrant behaviour of the chromatin materials in the PMCs (Gottschalk 1970, Morriset 1978). 
The microphotograph (Fig. 1) indicated that the cytokinesis was undergoing its normal course of division, that is, the telophase was triggered at its scheduled time and space, but the metaphase-anaphase in these cases were delayed, giving rise to erratic movement of the chromatin materials.

The possibility of precocious cytokinesis or commencement of telophase, leading to the formation of two sister dyads has to be ruled out completely, since in all such cases the cytoplasm contained in each of the dyads appeared normal in shape, size and probably also in function, because each of the sister dyads was covered in a well developed and defined wall, which was a cytoplasmic product. Thus the precocious cytokinetic division has to be ruled out in the present context.

The occurrence of such types of aberrant dyads might be due to the delay in the chromatin movement. This, however, cannot be attributed to prolonged synaptic phase between the bivalents or induction of stickiness or any other aberration in the chromosomes, which might intervene in the normal chromatin movement during the anaphase-telophase stage, because in all such cases chromatin bridges, laggards and fragments would have been observed and since these were completely absent in the present investigation, rules out such possibility.

The retarded movement of the chromatin materials in the PMCs under discussion might be assumed to be due to changes induced in the kinetochores or its activities. This view was based on the fact that the movement of the chromatin materials was a gene or genes controlled mechanism. This supports the proposal of Luykx (1970) who has put forward an appealing speculation that the kinetochore was a gene product and its activities were genetically controlled. On the other hand, the kinetochore contained the genetic material was demonstrated by Feulgen positive reaction and hybridization experiments by Kezer and Macgregor (1971). Similar types of aberration in the PMCs have also been recorded by Bobak and Henrich (1978). They have considered such phenomenon as a genetical event, and could be effectively brought about by the action of mutagens like lauryl alcohol and trifluraline. The gamma irradiations used in the present investigation have effectively influenced the gene or the genes responsible for the kinetochore formation and thus its activity which was in exponential relationship with the dose applied. Similarly, the delayed movement of the chromosomes has been observed by Walters (1958) in Bromus hybrids, such retarded movements in the chromosomes have been assumed to be due to the changes induced in the kinetochoric activities. In the present case the delayed chromosome movement would lead to prolongation of anaphase. The telophase was triggered at this stage in its scheduled time and space forming two sister dyads still connected by a thin strip of cytoplasm. Since the polarity of these dyads remained the same but shifted in position due to cytokinesis, the chromatin set lying nearer the pole migrated in the normal fashion, while the set having increased pole distance was in the process of migration to its destined pole (Dietz 1972). Any change in the polarity could only be possible after the PMCs had completed the meiotic I division.

Such conditions appeared as extrusion or mixing of the chromatin materials and thus connoted as cytomixis by Gates (1911). Cytomixis in the literal sense in these contexts appeared as misnomer. 


\section{Acknowledgements}

The author wishes to extend his sincere thanks to Dr. S. S. N. Sinha, Rajendra Agricultural University, Pusa, Bihar, for his supervisions. Sincere thanks are also due to Mrs. N. Bariar for going over the manuscript, valued criticisms and her co-operations.

\section{Bibliographies}

Bell, C. R. 1974. Cytomixis in Tauschia nudicaulis Schlecht (Apiaceae). Cytologia 29: 396-398. Bobak, M. and Henrich, R. 1978. Cytomixis as a manifestation of pathological changes after the application of Triflualine. The Nucleus 21: 20-26.

Dietz, R. 1972. Die Assembly-Hypothese der Chromosomenbewegung und Veränderungen der Spindellage während der Anaphase I in Spermatocyten von Pales ferruginla. Chromosoma 38: 11-76.

Gates, R. R. 1911. Pollen formation in Oenothera gigas. Ann. Bot. 25 : 909-940.

Gottschalk, W. 1970. Chromosome and nuclear migration during microsporogenesis of Pisum sativum. The Nucleus 13: 1-9.

Kamra, O. P. 1960. Chromatin extrusion and cytomixis in pollen mother cells of Hordeum. Hereditas 46: 592.

Kezer, J. and Macgregor, H. C. 1971. A fresh look at meiosis and centromeric heterochromatin in the red backed salamander Plethodon cinreus. Chromosoma 33: 146-166.

Luykx, P. 1970. Cellular mechanism of chromosome distribution. Academic Press, N. Y., Int. Rev. Cytol. (Supplement): 173.

Morriset, P. 1978. Cytomixis in pollen mother cells of Ononis. Leguminosae. Can. Jour. Genet. Cytol. 20: 383-388.

Walters, M.S. 1958. Aberrant chromosome movement and spindle formation in meiosis of Bromus hybrids. An interpretation of spindle organisation. Amer. J. Bot. 45: 271-289. 